Publisher: Taylor \& Francis \& British Poultry Science Ltd

Journal: British Poultry Science

DOI: $10.1080 / 00071668.2014 .991274$

$$
\text { CBPS-2014-224 }
$$

Ed. Kjaer, October 2014;

Edited Hocking 13 November 2014

\title{
Welfare indicators during broiler slaughtering
}

C. GRILLI, A.R. LOSCHI, S. REA, R. STOCCHI, L. LEONI ${ }^{1}$ AND F. CONTI ${ }^{1}$

School of Biosciences and Veterinary Medicine, University of Camerino, Via

Circonvallazione 93/95 - 62024 Matelica (MC) and 1 Azienda Sanitaria Locale, Via Gallodoro 68 - 60035 Jesi (AN), Italy

\section{Running title: Broiler welfare during slaughtering}

Correspondence to: Claudia Grilli, School of Biosciences and Veterinary Medicine, University of Camerino, Via Circonvallazione 93/95 - 62024 Matelica (MC), Italy.

E-mail: claudia.grilli@studenti.unicam.it 
Abstract 1. The aim of this study was to identify the most relevant welfare indicators for unloading, lairage, stunning, killing and post-mortem inspection in a poultry slaughter plant. Different indicators were unloading duration, lairage time, environmental variables in the lairage facilities, shackling time and electrical variables used in the water bath.

2. Lairage time did not correlate strongly with dead on arrival. Heat stress was limited by means of ventilation systems, correct cage placement and appropriate stocking density per crate. The acceptable shackling period was about $30 \mathrm{~s}$.

3. The presence of a corneal reflex showed that an animal was alive, while spontaneous wing flapping, spontaneous eye blinking and response to a painful stimulus were regarded as indicators of stunning efficiency.

4. It was concluded that the presence of recent traumatic injuries during the post-mortem inspection could be a valid means to establish whether corrective measures concerning the handling, transport and loading procedures should be taken.

\section{INTRODUCTION}

The protection of animals at the time of slaughter is covered by the EC Regulation No $1099 / 2009$ of 24 September 2009 entered into force in 1. January 2013. Business operators, involved in the killing of animals, must respect the correct practices to avoid pain and minimise suffering. Moreover, failure to comply with animal welfare could indirectly have an adverse impact on meat quality (Grandin, 2013).

To prevent stress, animals should be unloaded as quickly as possible after arrival at the slaughter plant. Containers must be in good repair without broken plastic parts which might cause injuries, and must be emptied mechanically in a horizontal position. Stability and ventilation must be assured. Lairage facilities should be designed and constructed so that the welfare of animals is constantly ensured and sudden noises must be minimised. The exposure to noise stimuli induces a significant increase of corticosterone concentration in blood plasma (Mitchell, 2006; Chloupek et al., 2008). During pre-slaughter lairage birds may be exposed to 
a variety of potential stressors such as enclosure, strong light, fasting, withdrawal of water, stocking density and lairage time that could increase the mortality rate (Bayliss and Hinton, 1990). After lairage the cages are tipped over automatically, animals are dropped into a conveyor and finally they are hung on a shackle line. The shackle line must be positioned so that the disturbance is reduced to a minimum. Moreover, according to the EC Regulation No 1099/2009, birds suspended on the shackle line must not remain hung longer than one minute before immersion in the water bath. Gregory and Bell (1987) recommend a shackling period of $12 \mathrm{~s}$ maximum to reduce wing flapping. This is an indicator of fear and stress and in addition has economic consequences in case of broken wings and bruises (Jones and Satterlee, 1996). A further poultry welfare indicator during hanging is vocalisation (Debut et al., 2003). Another crucial factor, able to compromise animal welfare, is inappropriate water bath stunning. Stunning is required to induce unconsciousness and insensibility until death (EFSA, 2004) and its effects must persist for at least 45 s (EFSA, 2012). The effectiveness of stunning is influenced by electrical variables such as frequency, voltage, current and wave form, the resistance of birds and the dimensions of the water bath (Kranen et al., 1996). According to Prinz et al. (2012) the most relevant indicators to assess the effectiveness of stunning are corneal reflex, spontaneous eye blinking, spontaneous wing flapping, presence of breathing and response to a painful stimulus. After stunning, birds must be killed manually or by means of automatic neck cutters that sever carotid arteries in the neck, as stated by the EC Regulation No 1099/2009. Grandin (2011) suggests that post-mortem inspection is possible to detect old injuries attributable to poor welfare conditions at farm level and recent damage indicating incorrect catching and handling practises.

There is little research regarding transport, lairage and slaughter of broilers in Mediterranean climatic conditions and more investigation is needed. This study investigated the effects of environmental conditions on bird welfare at the time of slaughtering. The objective was to identify the most important welfare indicators during unloading, lairage, 
stunning, killing and post-mortem inspection and to provide a practical approach to evaluate birds' welfare at the time of killing. Welfare was also assessed to establish the effects of lairage time, especially on the number of dead on arrival (DOA).

\section{MATERIALS AND METHODS}

The study was conducted on 233 batches of poultry and in each batch a sample of 100 animals was examined, for a total of 23300 broilers. The research was carried out in an Italian poultry slaughter plant, from May 2013 to September 2013, with the collaboration of the Official Veterinarian. The processing plant could slaughter 7200 broilers per h. They were male Ross broilers, $55 \mathrm{~d}$ old with body weights of about $3.5 \mathrm{~kg}$. Welfare was evaluated during antemortem and post-mortem inspection. During unloading, duration time and discharge method were considered. In the lairage facilities relative humidity $(\mathrm{RH})$ and temperature were recorded with 4 wireless probes (iButton Temperature Logger DS1920, Maxim Integrated, CA, USA). Data were downloaded and inserted in graphs by means of a specific adapter. The lighting was monitored with a light meter (LX-1010B, Mastech, Taiwan). The number of broken cages, of dead animals and of broilers with thermal stress was recorded. Thermal stress was investigated by measuring environmental variables in the lairage and by observing birds to detect dyspnea and/or polypnea (panting, gaping, high respiration rates). Stocking density, as established by EC Regulation No 1/2005, was evaluated on $50 \%$ of containers, about 250 cages (modular systems 4S-5S, Stork, Germany). Available space was calculated as $\mathrm{cm}^{2} / \mathrm{kg}$ of live weight by dividing the floor surface of cages by the total body weight of birds inside.

Welfare indicators analysed during poultry hanging were: suspension time, percentage of vocalising animals and wing flapping before immersion in the water bath. Particular attention was paid to the electrical stunning. The water bath used a pulsed waveform and had a capacity of 28 animals. The birds were exposed to a current of $350 \mathrm{~Hz}$ and $120-150 \mathrm{~V}$ for 14 s. Each animal received a mean of $99.6 \mathrm{~mA}$. 
After the electrical values had been measured, the effectiveness of stunning was tested $3 \mathrm{~s}$ after the water bath exit using indicators such as spontaneous wing flapping, corneal reflex, spontaneous eye blinking and response to a painful stimulus. The corneal reflex was tested by touching the bird's cornea to assess blinking. By placing a finger in front of the eye, the spontaneous movement of the nictitating membrane could be observed. A hard pinch delivered to the comb was used to observe the reaction to a painful stimulus. The interval between stunning and killing was measured. During post-mortem inspection welfare was assessed by counting broken wings, bruises, foot pad lesions and green discoloured thighs due to the rupture of gastrocnemius tendon. The last two may indicate health problems at farm level. Foot pad lesions may be related to the quality and management of litter and the performance of drinking systems. Gastrocnemius tendon breakage can be caused by synovitis or virus infection.

Data were recorded on check-lists and imported to spread sheets for analysis. Minimum, mean, maximum percentage and standard deviation were calculated for each variable using Microsoft Office Excel (Microsoft Co., Redmond, WA, USA). The lairage time for each flock was linked to corresponding DOAs, to find specific correlations using least squares.

\section{RESULTS}

No anomalies were detected during unloading: every cage was handled with care and was not dropped or tilted. Waiting time in the processing plant before mechanical discharge was at most 12 min. Mean unloading time was 12 min. Regarding lairage time, the minimum, mean and maximum values were $0.17,4.04$, and $9.43 \mathrm{~h}$, respectively. The graph of data dispersion (Figure) shows that the DOA value is not specifically correlated with lairage duration, although mortality was higher in a flock subjected to a lairage time of $8.29 \mathrm{~h}$.

Figure near here 
Data dispersion was examined using standard mathematic functions and the specific coefficient of determination $R^{2}$ was calculated as a maximum value of 0.003 for a quadratic approximation. This was insufficient to define a specific mathematical correlation.

The mean incidence of DOA was $0.40 \%$ with minimum and maximum values of 0.05 and $1.65 \%$, respectively. Table 1 shows the environmental variables in the lairage facilities: mean temperature was $24.9^{\circ} \mathrm{C}$ and indoor relative humidity $60 \%$. The mean percentage of broilers with heat stress was $16.9 \%$ and the mean proportion of broken cages was $2.3 \%$. Shackling time before immersion in the water bath was $30 \mathrm{~s}$ while the incidence of vocalisations and wing flapping was 14.3 and $4.9 \%$, respectively.

Table 2 summarises the welfare indicators related to stunning. The interval between stunning and killing was $8 \mathrm{~s}$ with automatic neck cutters and $12 \mathrm{~s}$ with manual sticking. The post-mortem data are shown in Table 3.

Tables 1, 2 and 3 near here

\section{DISCUSSION}

There was no optimum period in lairage which ensured a constant low value of mortality, which is in line with the findings of Bianchi et al. (2005) and Vieira et al. (2011). They found lairage duration did not affect DOA if the environmental values were controlled in the holding area. The mortality results are in accordance with those of Petracci et al. (2006) reporting an average DOA of $0.35 \%$ with a minimum of $0.04 \%$ and maximum of $2.00 \%$. Grandin (2009) defines a mortality percentage of $0.5 \%$ as "acceptable" and of $0.25 \%$ as "excellent".

Our study supports the importance of controlling environmental values pre-slaughter to avoid thermal stress, in accordance with Bayliss et al. (1990), though no published data defining an acceptable percentage of broilers with heat stress in transport containers have been found. Ventilation and nebulisation systems and placing containers correctly in the holding area can reduce heat stress, ensuring an adequate air flow. EFSA (2011) recommends, in broiler transport containers, a maximum of $24-25^{\circ} \mathrm{C}$ assuming a relative humidity of $70 \%$. The stocking density was $192 \mathrm{~cm}^{2} / \mathrm{kg}$, which is higher than the $115 \mathrm{~cm}^{2} / \mathrm{kg}$ required by EC 
Regulation No $1 / 2005$. Thus birds had enough space to lie down at the same time without overlapping each other. The condition of the cages met the requirement of Grandin (2009), who recommended that $95 \%$ of broiler transport crates must be undamaged. Shackling times before immersion in the water bath were similar to those suggested by Bedanoval et al. (2007), who recommended times between 12 to $60 \mathrm{~s}$.

The percentage of vocalisation and wing flapping shows that fear and stress were moderate. Light levels were low in the hanging area to facilitate the relaxation of birds, reducing violent struggling and wing flapping, as reported by Jones (1996).

Although electrical stunning values did not meet EC Regulation No 1099/2009 requirements, they complied with the Italian Ministerial Note of 7 January 2013. According to this, until 8 December 2019, the Competent Authority may authorise the use of electrical values lower than EC Regulation No 1099/2009 if animal welfare is respected.

A positive corneal reflex shows an animal is alive (Raj et al., 2006) but does not demonstrate it is conscious. Our findings are consistent with those of Prinz et al. (2010), according to which there should be no more than $30 \%$ of positive responses under commercial conditions. The incidence of spontaneous wing flapping was moderate with an average of 4.9\%. This indicator of stress and escaping attempt is present in conscious animals.

The rates of spontaneous eye blinking were lower than those of Prinz et al. (2010) who considered a percentage of no more than $15 \%, 20 \mathrm{~s}$ after exit from the water bath, as acceptable. This lack of pain perception confirms unconsciousness, as demonstrated by Erasmus et al. (2010), who considered that conscious animals usually exhibit voluntary actions and involuntary reflex reactions in response to painful stimuli, whereas largely insensible animals exhibit only involuntary reflex reactions.

In the present study the mean percentage of broilers with at least one kind of reflex was $37 \%$, which seems high and could indicate the ineffectiveness of stunning. However, although the corneal reflex showed the highest average incidence (31\%), it is regarded by 
EFSA (2013), despite its high sensitivity and specificity, not as a recommended indicator but as an additional one in between exit from the water bath stunner and neck cutting. It is not always easy to distinguish between the corneal and the palpebral reflex because of the speed of the processing line; both need to be evaluated and this should help in determining the animal's level of consciousness. Further research is necessary to validate stunning efficiency indicators as the sensitivity and specificity of those investigated here are not optimal.

The interval between stunning and killing must be brief to prevent birds recovering. The proportion of broken wings in our study was higher than the maximum value of $3 \%$ suggested by Grandin (2009). The average percentage of animals with at least one kind of traumatic injury detected during post-mortem inspection was 10\%. Moran and Berry (1988) found the mean percentage of injuries was about 10-15\%, whereas Kettlewell and Turner (1985) reported a value of 5\%. Elrom (2001) regarded even the latter value to be alarming. Bremner and Johnston (1996) found that catching was responsible for only a minor part (3\%) of the damage, whereas processing techniques played the major role $(96 \%)$. Thus our findings show the need to improve catching, but particularly transport, unloading and slaughtering, in order to avoid suffering and to reduce economic damage. The mean percentage of birds with foot pad lesions and tendon breakage was 5.6\% and did not indicate serious health problems at farm level.

In conclusion, this study shows it is possible to ensure poultry welfare, if attention is paid to every stage during pre-slaughter. Lairage time does not appreciably affect DOA. Monitoring environmental variables in the holding area reduces the potential stressful effects of lairage time. Effective ventilation systems, placing cages correctly and appropriate stocking density per crate can limit heat stress. Furthermore, to improve the animal welfare at the slaughterhouse it is necessary to reduce sudden noises and strong lighting in lairage facilities and to control the suspension time and the efficacy of stunning. An acceptable shackling time, to reduce pain and stress, is about $30 \mathrm{~s}$. Among the signs of consciousness, a corneal reflex 
shows the bird is alive, while spontaneous wing flapping, spontaneous eye blinking and response to a painful stimulus must be evaluated to verify the stunning efficacy. Finally, assessing poultry welfare at the processing plant can help to identify poor welfare conditions both at the farm, and during slaughtering, thus showing that structural or managerial improvements are needed at either or both sites.

\section{REFERENCES}

BAYLISS, P.A. \& HINTON, M.H. (1990). Transportation of poultry with special reference to mortality rates. Applied Animal Behaviour Science, 28: 93-118.

BEDANOVAL, I., VOSLAROVA, E., CLOUPEK, P., PISTEKOVA, V., SUCHY, P., BLAHOVA, J., DOBSIKOVA, R. \& VECEREK, V. (2007). Stress in broilers resulting from shackling. Poultry Science, 87(6): 1065-1069.

BIANCHI, M., PETRACCI, M. \& CAVANI, C. (2005). Effects of transport and lairage on mortality, liveweight loss and carcass quality in broiler chickens. Italian Journal of Animal Science, 4: 516-518.

BREMER, A. \& JOHNSTON, M. (1996). Poultry Meat Hygiene and Inspection. W.B Saunders Company Ltd, London, UK.

CHLOUPEK, P., VOSLAROVA, E., CHLOUPEK, J., BADANOVA, I., PISTEKOVA, V. \& VECEREK, V. (2008). Stress in broiler chickens due to acute noise exposure. Acta Veterinaria Brno, 78: 93-98.

DEBUT, M., BERRI, C., BAÈZA, E., SELLIER, N., ARNOULD, C., GUÈMENÈ, D., JEHL, N., BOUTTEN, B., JEGO, Y., BEAUMONT, C. \& LE BIHAN-DUVAL, E. (2003).

Variation of chicken technological meat quality in relation to genotype and preslaughter stress conditions. Poultry Science, 82: 1829-1838.

EC REGULATION No 1/2005 OF 22 DICEMBER 2004. Council Regulation (EC) No $1 / 2005$ on the protection of animals during transport and related operations and amending 
Directives 64/432/EEC and 93/119/EC and Regulation (EC) No 1255/97. Official Journal of the European Union No L 3 of 5 January 2005.

EC REGULATION No 1099/2009 OF 24 SEPTEMBER 2009. Council Regulation (EC) No $1099 / 2009$ on the protection of animals at the time of killing. Official Journal of the European Union No L 303 of 18 November 2009.

EFSA (2004). Opinion of the Scientific Panel on Animal Health and Welfare on a request from the Commission related to welfare aspects of the main systems of stunning and killing the main commercial species of animal. The EFSA Journal, 45: 1-29.

EFSA (2011). Scientific opinion concerning the welfare of animals during transport. The EFSA Journal, 125 (9):1966.

EFSA (2012). Scientific opinion on the electrical requirements for water bath stunning equipment for poultry. The EFSA Journal, $\mathbf{1 0}(6): 2757$.

EFSA (2013). Scientific opinion on monitoring procedures at slaughterhouse for poultry. The EFSA Journal, 11 (12): 3521.

ELROM, K. (2001). Handling and transportation of broiler welfare, stress, fear and meat quality. Israel Journal of Veterinary Medicine, 56 (2).

ERASMUS, M.A., TURNER P.V. \& WIDOWSKI T.M. (2010). Measures of insensibility used to determine effective stunning and killing of poultry. The Journal of Applied Poultry Research, 19: 288-298.

GRANDIN, T. (2009). Poultry slaughter plant and farm audit: critical control points for bird welfare. http://www.grandin.com/poultry.audit.html

GRANDIN, T. (2011). Animal welfare audits for cattle, pigs and chicken that use the HACCP principles of critical control points with animal based out come measures. Improving animal welfare: a practical approach. CABI Publishing, Wallingford. http://www.grandin.com/welfare.audit.using.haccp.html 
GRANDIN, T. (2013). The effect of economics on the welfare of cattle, pigs, sheep and poultry. http://www.grandin.com/welfare/economic.effects.welfare.html

GREGORY, N.G. \& BELL, J.C (1987). Duration of wing flapping in chickens shackled before slaughter. Veterinary Record, 121: 567-569.

JONES, R.B. \& SATTERLEE, D.G. (1996). Restricted visual input reduces struggling in shackled broiler chickens. Animal Behaviour, 52: 109-117.

JONES, R.B. (1996). Fear and adaptability in poultry insights, implication and imperatives. Poultry Science, 52: 131-147.

KETTLEWELL, P.J. \& TURNER M.J.B. (1985). A review of broiler chicken catching and transport systems. Journal of Research and Applications in Agricultural Engineering, 31: 93-114.

KRANEN, R.W., VEERKAMP, C.H., LAMBOOY, E., VAN KUPPVELT, T.H. \& VEERKAMP, J.H. (1996). Haemorrhages in muscle of broiler chickens: the relationships among blood variables at various rearing temperature regimens. Poultry Science, 75: 570576.

MINISTERIAL NOTE OF 7 JANUARY 2013. First indications about the application of EC Regulation No 1099/2009 concerning the protection of animals at the time of killing. DGSAF 0000213. Italian Ministry of Health.

MITCHELL, M.A. (2006). Influence of pre-slaughter stress on animal welfare processing efficiency. World's Poultry Science Journal, 62, Suppl. 254.

MORAN, P. \& BERRY, P. (1988). New developments in broiler harvesting. Science and the poultry industry. Agricultural and Food Research Council, London, 26-27.

PETRACCI, M., BIANCHI, M., CAVANI, C., GASPARI, P. \& LAVAZZA, A. (2006). Preslaughter mortality in broiler chickens, turkeys, and spent hens under commercial slaughtering. Poultry Science, 85 (9): 1660-1664. 
PRINZ, S., VAN OIJEN, G., EHINGER, F., BESSEI, W. \& COENEN, A. (2010). Effects of water bath stunning on the electroencephalograms and physical reflexes of broilers using a pulsed direct current. Poultry Science, 89: 1257-1284.

PRINZ, S., VAN OIJEN, G., EHINGER, F., BESSEI, W. \& COENEN, A. (2012). Electrical water bath stunning: influence of different waveform and voltage settings on the induction of unconsciousness and death in male and female broiler chickens. Poultry Science, 91: 998-1008.

RAJ, A.B.M., O'CALLAGHAN, M. \& KNOWELES, T.G. (2006). The effects of amount and frequency of alternating current used in water bath stunning and of slaughter methods on electroencephalograms in broiler. Animal Welfare, 15: 7-18.

VIEIRA, F.M.C., SILVA, I.J.O., BARBOSA, FILHO J.A.D. \& VIEIRA, A.M.C., BROOM, D.M. (2011). Preslaughter mortality of broilers in relation to lairage and season in a subtropical climate. Poultry Science, 90: 2127-2133. 


\section{FIGURE LEGENDS}

Figure. Data dispersion graph: correlation between dead on arrival (DOA) and lairage time. Indicators represent single flocks coming from the same farm to the slaughter plant. Each value is an aggregate value of more batches.

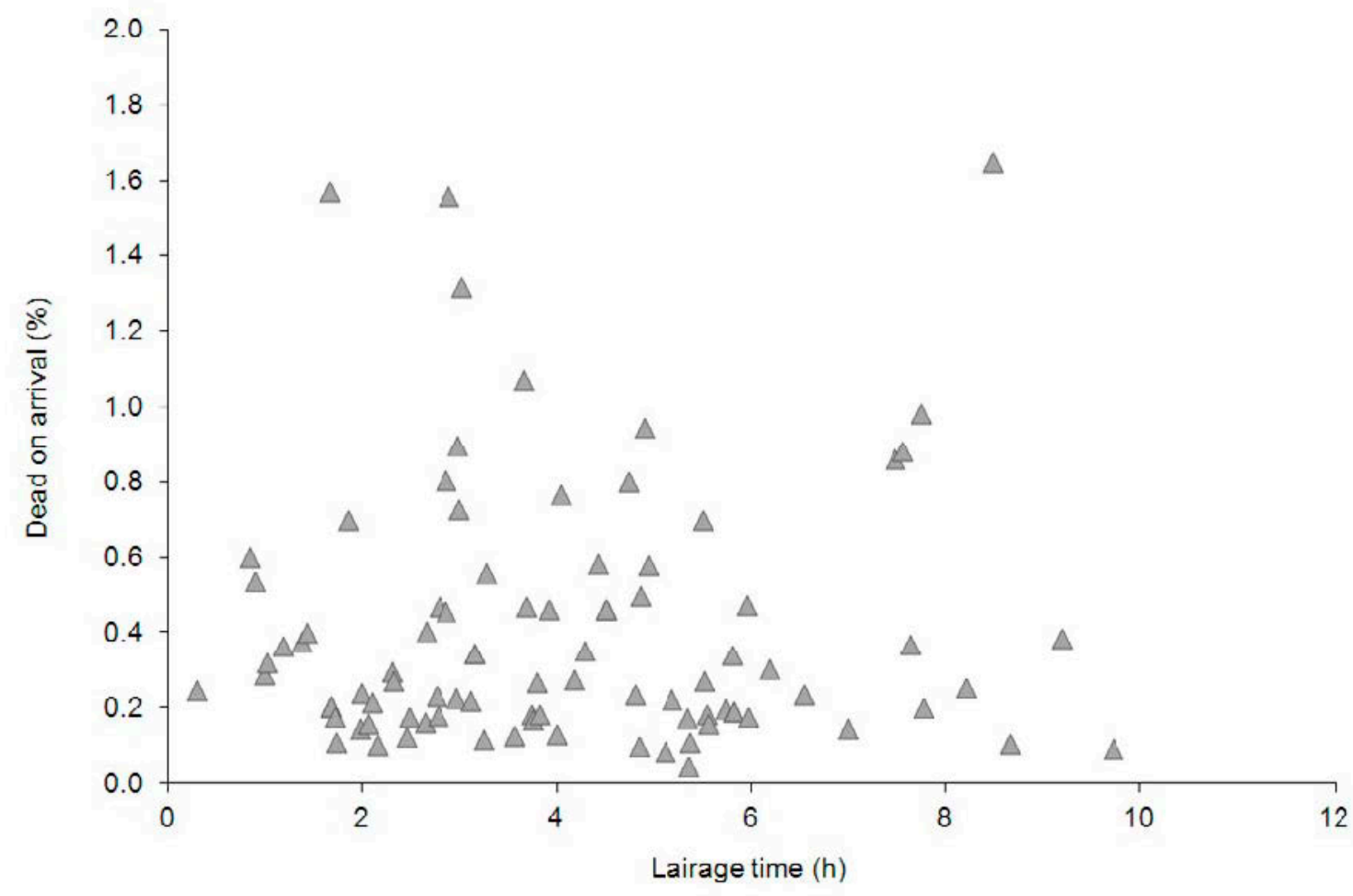


Table 1. Environmental variables in lairage facilities

\begin{tabular}{llll}
\hline Variable & Minimum & Mean & Maximum \\
& value & value & value \\
\hline Temperature $\left({ }^{\circ} \mathrm{C}\right)^{1}$ & 18.0 & 25.4 & 31.0 \\
Indoor relative humidity $(\%)^{1}$ & 51.0 & 60.0 & 83.9 \\
Outdoor relative humidity (\%) & 53.0 & 63.6 & 85.7 \\
Illuminance (lx) & 13.0 & 90.0 & 228.0 \\
\hline
\end{tabular}

${ }^{1}$ Temperature and humidity were recorded with 4 wireless probes: one placed outdoors and three indoors in the centre, right and left side of plant. 
Table 2. Welfare indicators during stunning

\begin{tabular}{lllll}
\hline Welfare indicators & $\begin{array}{l}\text { Minimum } \\
\text { value }\end{array}$ & $\begin{array}{c}\text { Mean } \\
\text { value }\end{array}$ & Maximum & Standard \\
& 16.0 & 31.0 & 47.0 & 6.6 \\
\hline Corneal reflex (\%) & 4.9 & 29.0 & 5.3 \\
Spontaneous wing flapping (\%) & 0.0 & 1.1 & 4.0 & 0.8 \\
Spontaneous eye blinking (\%) & 0.0 & 0.0 & 0.0 & 0.0 \\
Response to painful stimulus (\%) & 0.0 & & &
\end{tabular}

${ }^{1}$ Values concerning a single broiler flock.

${ }^{2}$ Values referring to the average of 233 broiler batches. 
Table 3. Welfare indicators during post-mortem inspection

\begin{tabular}{lllll}
\hline Welfare indicators & $\begin{array}{l}\text { Minimum } \\
\text { value }\end{array}$ & $\begin{array}{l}\text { Mean } \\
\text { value }^{2}\end{array}$ & $\begin{array}{l}\text { Maximum } \\
\text { value }^{1}\end{array}$ & $\begin{array}{l}\text { Standard } \\
\text { deviation }\end{array}$ \\
\hline Broken wings (\%) & 2.0 & 7.8 & 26.0 & 3.5 \\
Haematomas (\%) & 0.0 & 2.2 & 5.0 & 1.7 \\
Foot pad lesions (\%) & 0.0 & 4.6 & 46.0 & 7.3 \\
Tendon breakage (\%) & 0.0 & 1.0 & 8.0 & 2.0 \\
& & & & \\
\hline
\end{tabular}

${ }^{1}$ Values concerning a single broiler flock.

${ }^{2}$ Values referring to the average of 233 broiler batches. 